\title{
The Role of Kisspeptin in Female Reproduction
}

\author{
Sareh Zeydabadi Nejad, ${ }^{1}$ Fahimeh Ramezani Tehrani, ${ }^{1}$ and Azita Zadeh-Vakili ${ }^{2,}{ }^{*}$ \\ ${ }^{1}$ Reproductive Endocrinology Research Center, Research Institute for Endocrine Sciences, Shahid Beheshti University of Medical Sciences, Tehran, IR Iran \\ ${ }^{2}$ Cellular and Molecular Endocrine Research Center, Research Institute for Endocrine Sciences, Shahid Beheshti University of Medical Sciences, Tehran, IR Iran \\ "Corresponding author: Azita Zadeh-Vakili, PhD, Cellular and Molecular Endocrine Research Center, Research Institute for Endocrine Sciences, Shahid Beheshti University of \\ Medical Sciences, Tehran, IR Iran. Tel: +98-2122432513, Fax: +98-2122402463, E-mail: azitavakili@endocrine.ac.ir
}

Received 2016 November 27; Revised 2017 February 20; Accepted 2017 March 09.

\begin{abstract}
Context: Kisspeptin (KISS1), a recently discovered neuropeptide that acts upstream of gonadotropin-releasing hormone (GnRH) neurons, is critical for maturation and function of the reproductive axis. This review aimed at providing comprehensive and up-todate information on Kisspeptin and its role in female reproduction.

Evidence Acquisition: A literature review was performed using PubMed for all English language articles published between 1999 and 2016.

Results: The kisspeptin system (KISS1/G protein-coupled receptor-54,GPR54) has recently been addressed as an essential gatekeeper of puberty onset and gonadotropin secretion. Compelling evidence has documented that hypothalamic Kisspeptin mediates steroid feedback and metabolic cues at different developmental stages throughout lifespan. Furthermore, in pre/postnatally androgenized animal models, which exhibit many of the characteristics of Polycystic Ovarian Syndrome (PCOS), the hypothalamic expression of KISS1 and GnRH is abnormal, which might lead to multiple tissue abnormalities observed in this disorder.

Conclusions: Kisspeptin, a principal activator of GnRH neurons and the target of endocrine and metabolic cues, is a prerequisite for the onset of puberty and maintenance of normal reproductive function, as abnormal KISS1/GPR54 system has been reported in both animal models and patients with certain forms of infertility, e.g. Idiopathic Hypogonadotropic hypogonadism (IHH) and PCOS. The information suggests that kisspeptin or its receptor represents a potential therapeutic target in the treatment of patients with fertility disorders.
\end{abstract}

Keywords: Kisspeptin, GPR54, HPG Axis, Reproduction, Puberty

\section{Context}

The Hypothalamic-Pituitary-Gonadal (HPG) axis controls all stages of reproduction. The hypothalamus produces gonadotropin-Releasing Hormone (GnRH), which travels to the anterior pituitary and stimulates Luteinizing Hormone ( $\mathrm{LH}$ ) and Follicle-Stimulating Hormone(FSH) secretion. Slow GnRH pulsatility favors FSH secretion and fast pulse frequencies support LH secretion (1). Amounts of these hormones vary widely at different ages and different times during the menstrual cycle of females $(2,3)$. LH and FSH, in turn control gametogenesis, and steroidogenesis. Gonadal steroids, in turn, modify GnRH neuronal function via negative and positive feedback action (4). It has recently been revealed that hypothalamic Kisspeptin acts upstream of GnRH and mediates sex steroid feedback and metabolic input on the reproductive axis. This neuropeptide is required for puberty onset and maintenance of normal reproductive function, as loss-of-function mutations of kisspeptin receptor gene (KISS1R) are associated with pubertal failure, e.g. Idiopathic Hypogonadotropic hypogonadism (IHH) (5). In addition, based on data from Polycystic Ovarian Syndrome (PCOS) in animal models and patients, alterations in Kisspeptin signaling may contribute to the generation of PCOS phenotype (6). Manipulating Kisspeptin signaling may provide novel potential therapeutic strategies to treat fertility disorders related to both decreased and increased GnRH signaling. This review summarizes current knowledge available on the physiological role of Kisspeptin in reproduction and reproductive disorders. Additionally, age-related changes in Kisspeptin signaling are discussed, with a focus on female studies.

\section{Evidence Acquisition}

This literature review was initiated during September 2015 based on PubMed English articles published between 1999 and 2016. There were no limitations regarding species and the focus was mostly on studies using female animals. Relevant search terms were used to identify the articles, including Kisspeptin, Hypothalamic-Pituitary-Gonadal axis, reproduction, and puberty.

\section{Results}

\subsection{History}

Kisspeptins are a number of structurally-related amidated peptides, which are derived from the differential 
proteolytic processing of a common precursor of 145 amino acids encoded by the KISS1 gene (7). Kisspeptins operate via binding and activation of the $G$ protein-coupled receptor, GPR54 (8). Metastin (also termed Kisspeptin 54) was for the first time identified in 1996 as a tumor metastasis suppressor in melanoma cell lines without affecting tumorigenicity (9). In 1999, GPR54 was cloned as an orphan receptor (not related to KISS1), due to an approximately $40 \%$ homology with galanin receptors (10). Two years later, the connection between kisspeptin54 and GPR54 was shown for the first time (11), at a time when the biological function of Kisspeptins was limited to their ability to repress tumor invasion (7). Kisspeptin has also been shown to regulate cell migration in pathological (tumors) and in physiological (trophoblast invasion in pregnancy) conditions (12). In 2003, inactivating mutations of the GPR54 were found in individuals with hypogonadotropic hypogonadism (13-15). So far, many studies have confirmed the key roles of Kisspeptin in the control of different aspects of reproduction (16-18).

\subsection{KISS1 Gene}

Human KISS1 gene maps to chromosome 1q32 and consists of 4 exons, of which only parts of the third and fourth exons are finally translated to a 145 -amino acid precursor peptide (19). This premature peptide is subsequently cleaved to 54 amino acids in length, which can be truncated to 14,13 , and 10 amino acid sequences. These peptides have the $\mathrm{C}$-terminal region in common, where they have an Arg-Phe-NH2 motif characteristic of the RF-amide peptide family. All Kisspeptins exhibit the same affinity for their corresponding receptor $(7,19)$. The longest peptide in mouse and rat is composed of 52 amino acids instead of 54 amino acids in humans (20).

In human placental tissue and cell lines, the KISS1 transcription start site (TSS) is located between -153 bp to - 156 bp upstream of the ATG. There are several promoter elements and binding sites for transcriptional factors in $5^{\prime}$ region of this site (21). Again, a TSS was detected in the hypothalamic KISS1 gene of rats, mice, nonhuman primates, and humans. There is an alternative TSS (TSS2) at the upstream of TSS1 in rat arcuate nucleus (ARC), creating a longer transcript. In contrast to TSS1-derived transcripts, the TSS2-derived transcript content did not change at puberty and after ovariectomy in female rats. Estrogen has no effect on TSS2-drived transcript expression, which may be due to a lack of promoter elements and binding sites for transcriptional factors in TSS2 (22).

In addition, there are GC-rich sites at -188 to -87 of the human KISS1 promoter for specific protein1 and 3 (Sp1 and Sp3) binding. These sites are critical for basal and Estradiol (E2)-induced KISS1 expression. The Sp1 and Sp3 pro- teins function together through dimerization. Sp1 trans activates KISS1 promoter activity, whereas Sp3 functions as a repressor. A different ratio of $\mathrm{Sp} 1$ to $\mathrm{Sp} 3$ leads to differential regulation of Kisspeptin expression. Higher ratios of Sp1 in AVPV and lower ratios of Sp1 in ARC may mediate positive and negative E2-induced Kisspeptin expression, respectively. In the absence of E2, Sp1/Sp3 complex binds to the GC-rich motif and stably stimulates KISS1 expression (20).

Evidence also showed that the KISS1 gene is controlled by CCAAT displacement protein (CDP, also known as CUTL1 and CUX1), Ying Yang 1 (YY1), Enhanced at Puberty 1 (EAP1), and Thyroid Transcription Factor 1 (TTF1). The CUX1 and YY1 are 2 Tumor Suppressor Gene (TSG) transcriptional regulators and TTF1 and Eap1 are 2 non-TSG transcriptional regulators. These 4 transcription factors interact with the KISS1 promoter in vivo and are expressed in Kisspeptin neurons. The CUX1 has different isoforms (e.g. p110 and p200) and can either repress or activate gene transcription. It has been shown that the KISS1 promoter is activated by TTF1 and CUX1-p200, and repressed by EAP1, YY1, and CUX1-p110. Table 1 shows the role of different gene products in KISS1 transcription (21).

Table 1. Regulators of KISS1 Expression

\begin{tabular}{lc}
\hline Activators & TTF1, CUX1-p200, Sp1, VIP, NKB \\
Suppressors & CUX1-p110, EAP1, YY1, Sp3, Eed, Cbx7, Prolactin \\
\hline
\end{tabular}

Like most genes, KISS1 may be subjected to mutations and polymorphisms. Some of these genetic variations have been recently identified in KISS1 gene. There are several reports showing the role for KISS1 mutations in the precocious puberty phenotype. Central Precocious Puberty is caused by the premature reactivation of the hypothalamic-pituitary-gonadal axis. Two KISS1 mutations, p.P74S and p.H90D, were identified as genetic causes of Central Precocious Puberty (CPP). The proline in position 74 is highly conserved among species and located in the amino-terminal region of Kisspeptin, within a PEST sequence. The p.P74S variant was detected in the heterozygous state in a male with very early pubertal development and was associated with higher Kisspeptin resistance to degradation, leading to an increased Kisspeptin bioavailability. The p.H90D variant was identified in the homozygous state in 2 unrelated females with CPP. The histidine in position 90 is not conserved and is located in the aminoterminal region of the Kisspeptin. This variant did not show increased bioactivity or resistance to degradation (23). Studies in China and Korea showed that p.P110T al- 
lele frequency was lower in females with CPP than in the controls (24). In another study in IRAN a novel variant, c.T148A, was reported within the coding regions of KISS1 gene (25). The c.G645CA mutation in the G-rich sequence located within the $3^{-}$-Untranslated Region (UTR) of the human KISS1 gene was also associated with CPP. Polymorphisms within the $3^{\prime}$-UTR of KISS1 influence its expression level through the regulation of the pre-mRNA 3 'end processing (26).

Furthermore, a homozygous mutation, N115K, was found in 4 affected family members with IHH. The asparagine in position 115 residue is conserved among all species and this replacement is predicted to damage protein function (27).

Polymorphisms in the promoter region may also impact KISS1 gene transcription. In the Guanzhong goats, the g.G1384A mutation in the KISS1 promoter was associated with litter size. The 1384A allele had greater Kiss1 mRNA levels than the $1384 \mathrm{G}$ allele in homozygous individuals and was predicted to change methylation and transcription factor-binding sites. Several other Single Nucleotide Polymorphisms (SNPs) in the goat KISS1 gene were also associated with litter size, suggesting the KISS1 gene as an excellent candidate for reproductive traits in livestock (28).

\subsection{Kisspeptin in the Hypothalamus}

\subsubsection{Kisspeptin and Gender Differentiation}

In mammals the anatomy and physiology of the neuroendocrine reproductive axis differs between the genders. There are also differences in various developmental stages of the animal's life, which indicates different upstream pathways, including Kisspeptin system, converging upon GnRH neurons (29). The Kisspeptin system is apparently critical for brain gender differentiation, acting through the regulation of postnatal T secretion.

Distribution of Kisspeptin neurons in the hypothalamus varies between species. In mammals there are 2 major regions of these neurons; a rostral one in the Pre-Optic Area (POA) and a caudal one in the arcuate nucleus, with proportionally more Kisspeptin neurons in the ARC than in the POA region $(4,30)$. In rodents, the POA regions are concentrated in the Anteroventral Periventricular Nucleus (AVPV). Anatomical differences between genders have been reported in the hypothalamus of some species, e.g. the rat AVPV is sexually dimorphic, with a greater number of KISS1 neurons in females compared to males (30). Like most sex differences in the brain, this sexual dimorphism is likely caused during the perinatal critical period by exposure to testosterone (or its metabolites) (31). Recent evidence has demonstrated that gonadectomy of male and female rats increased Kiss1 mRNA expression in the hypothalamus, and sex steroid replacement reversed this effect $(30,32)$. It has also been shown that KISS1 neurons express sex steroid receptors and are regulated by gonadal sex steroids, mediating the effects of estrogen on GnRH neurons; GnRH secretion is regulated by gonadal sex steroid feedbacks whereas GnRH neurons do not express the corresponding receptors. In female rodents, the AVPV mediates E2 positive feedback, causing occurrence of pre-ovulatory $\mathrm{GnRH} / \mathrm{LH}$ surge. Circadian cues also impinge upon AVPA, whereby KISS1 neurons in the AVPV receiving hormonal and temporal signals give rise to timely LH surge (30).

In contrast to AVPV, the arcuate nucleus shows no differences between males and females. The expression of KISS 1 in this region is inhibited by steroids, implying that these neurons have a role in the negative feedback regulation of gonadotropin secretion; however, in sheep the ARC is sexually dimorphic. Moreover, recent studies in mice, goats, sheep, and bovine demonstrate that ARC KISS1 neurons also express neurokinin $\mathrm{B}(\mathrm{NKB})$ and dynorphin; all these are referred to as KNDy neurons. These 3 neuropeptides may work together to regulate the pulsatile release of GnRH. It has been suggested that these 2 populations of KISS1 neurons are turned on during the GnRH surge, yet only ARC KISS1 neurons are activated during tonic or basal secretion of GnRH (33). Recent data has shown that Kisspeptin and dynorphin, within the KNDy neurons, control GnRH release during the menstrual cycle and mediate negative feedback of progesterone on GnRH neurons in bovine (9).

\subsubsection{Kisspeptin and Puberty}

Puberty is initiated through strengthening of excitatory cues and diminishing of inhibitory signs over GnRH neurons, creating a constant increase in pulsatile release of GnRH from hypothalamus. Increased GnRH pulsing activates the downstream elements causing a rise in gonadotropins and sex hormones, gametogenesis, secondary sex characteristics, and rapid growth that lead to the achievement of fertility (5). Timing of puberty onset is determined by genetic and environmental factors as well as gene-environment interactions, and is effectively different between males and females. It has been shown that puberty will not occur without proper interaction of Kisspeptins and their corresponding receptor, e.g. inactivating mutations of GPR54 gene in hypogonadotropic hypogonadism subjects (13-15).

Endogenous Kisspeptin rhythmicity and sensitivity to it increases at the time of puberty; in primates and rats, an increase in both the number of KISS1 neurons and the content of Kiss1 mRNA has been reported during juvenilepubertal transition $(29,34,35)$. Lomniczi et al. recently showed that increased methylation of Polycomb group 
(PCG) genes (KISS1 silencers) before puberty, evicted PcG proteins from the KISS1 promoter. This occurrence along with activating histone $\mathrm{H} 3$ modifications enhanced KISS1 expression (Figure 1) (36). Furthermore, epigenetic regulation of the KISS1 gene is reported to be involved in estrogenpositive feedback to generate $\mathrm{GnRH} /$ gonadotropin surge (37).

\subsection{Kisspeptin in the Pituitary}

Evidence for distribution of KISS1 and GPR54 containing cells in the pituitary is inconsistent $(5,32,38-40)$. In vitro studies of rat pituitary cells and of primary cell cultures derived from ovine, bovine, and porcine pituitaries, have described minor stimulatory effects of Kisspeptin on LH. For example, it was shown that KISS1 and GPR54 were expressed in rat gonadotrophs, which was differentially regulated by steroids. In females, KISS1 expression was upregulated by E2, while GPR54 expression was upregulated by GnRH and down-regulated by chronic exposure to E2 (41). In accordance with this study, molecular analysis of Kisspeptin signaling in mice showed that Kisspeptin induces $\mathrm{LH} \beta$ and $\mathrm{FSH} \beta$ gene expression, and this induction is protein kinase $C$ dependent and mediated by the immediate early genes (39). In addition, modest stimulatory effects of Kisspeptin on LH and GH secretion were reported in gonadotrophs and somatotrophs of peripubertal male and female rats (38). Evidence against this argument was documented by other reports. On the other hand, although intravenous (IV) administration of kisspeptin-10 activated LH release, pre-treatment with a GnRH-R antagonist blocked this effect (32). Similarly, in sheep, in which the hypothalamus and pituitary were surgically disconnected, IV administration of Kisspeptin failed to induce LH secretion (42). These may suggest that gonadotropes are not direct targets of Kisspeptin in vivo. Compelling evidence showed that co-administration of Kisspeptin and GnRH increased LH release (43). It should be noted that the direct stimulatory effects of Kisspeptin on pituitary and gonadotropin release are below that of GnRH, and the main stimulatory effect of Kisspeptin on gonadotrophin release is mediated via the hypothalamus.

\subsection{Kisspeptin in the Ovary}

\subsubsection{Kisspeptin and Ovulation}

The GnRH plays a central role in the reproductive system via stimulating the production of both $\mathrm{LH}$ and $\mathrm{FSH}$, with slow GnRH pulsatility ( $<1$ pulse per 2 to 3 hours) favoring FSH secretion and fast pulse frequencies $(>1$ pulse per hour) supporting LH secretion. Frequency of GnRH pulses varies throughout the menstrual cycle, thereby controlling the differential production of pituitary gonadotropins (1). The GnRH secretion is directly or indirectly modulated by many cues. Gonadal steroid feedback generally reduces $\mathrm{GnRH}$, except at the time of the preovulatory LH surge. Increased estrogen levels at the end of the follicular phase, besides activated progesterone receptors, activate KISS1 neurons in the AVPV thereby increasing GnRH pulse frequency and amplitude, leading to the $\mathrm{LH}$ surge and ovulation (30). Following ovulation, with rise in progesterone levels, GnRH pulse frequency slows, increasing $\mathrm{FSH}$ production.

Continuous expression of Kiss1 mRNAs is reported in the rat ovary, fluctuating during the estrous cycle, with a rise in the afternoon of proestrus; this could be blocked by administration of GnRH antagonist, preventing the pre-ovulatory LH surge. This occurrence can be brought back by human chorionic gonadotropin treatment, showing the timely ovarian expression of Kiss 1 by means of $\mathrm{LH}$ surge, suggesting that locally expressed Kisspeptin may be partly responsible for the control of ovulation. In addition, GPR54 mRNAs were detected at low levels in rat ovary, although they did not show a stage-specific pattern of expression (16). Similarly, KISS1 and Gpr54 mRNAs were detected in ovarian tissue of humans, monkeys and Siberian hamsters as well as cultured granulosa lutein cells, and also the expression of GPR54 in fish ovary. The relevance of the local KISS1/ GPR54 system may imply the positive contribution of this system in the regulation of ovarian function $(33,34)$. Considering the LH-dependent expression of many matrix metalloproteinases (MMPs) in the ovary, KISS1/GPR54 may partly support reproductive functioning through regulating MMP activity (44). Exposure of female Siberian hamsters to short photoperiods reduced KISS1 expression in the ovaries, and exposure to long day increased KISS1 and GPR54 protein levels. This photoperiod was associated with an increase in KISS1 and GPR54 and had a relationship with ovarian function restoration; the experience also indicated the possible role of KISS1/GPR54 in ovulation and/or recovery of ovarian function $(44,45)$.

In addition preovulatory LH surge increased BrainDerived Neurotrophic Factor (BDNF) in granulose cells, which with Kisspeptin signaling drives oocyte survival through the phosphatidylinositol 3-kinase/AKT (PI3K/AKT) pathway (46). In vitro analysis also showed that Kisspeptin treatment increased both basal and human chorionic gonadotropin (hCG)-stimulated progesterone secretion from cultured luteal cells, but not E2 production (Figure 2) (47).

\subsubsection{Kisspeptin and Pregnancy}

Dramatic increase in Kisspeptin concentration was also seen in human plasma during pregnancy, which was mainly produced in the placenta. On the other hand, his- 
Figure 1. Onset of Puberty in Female Rats

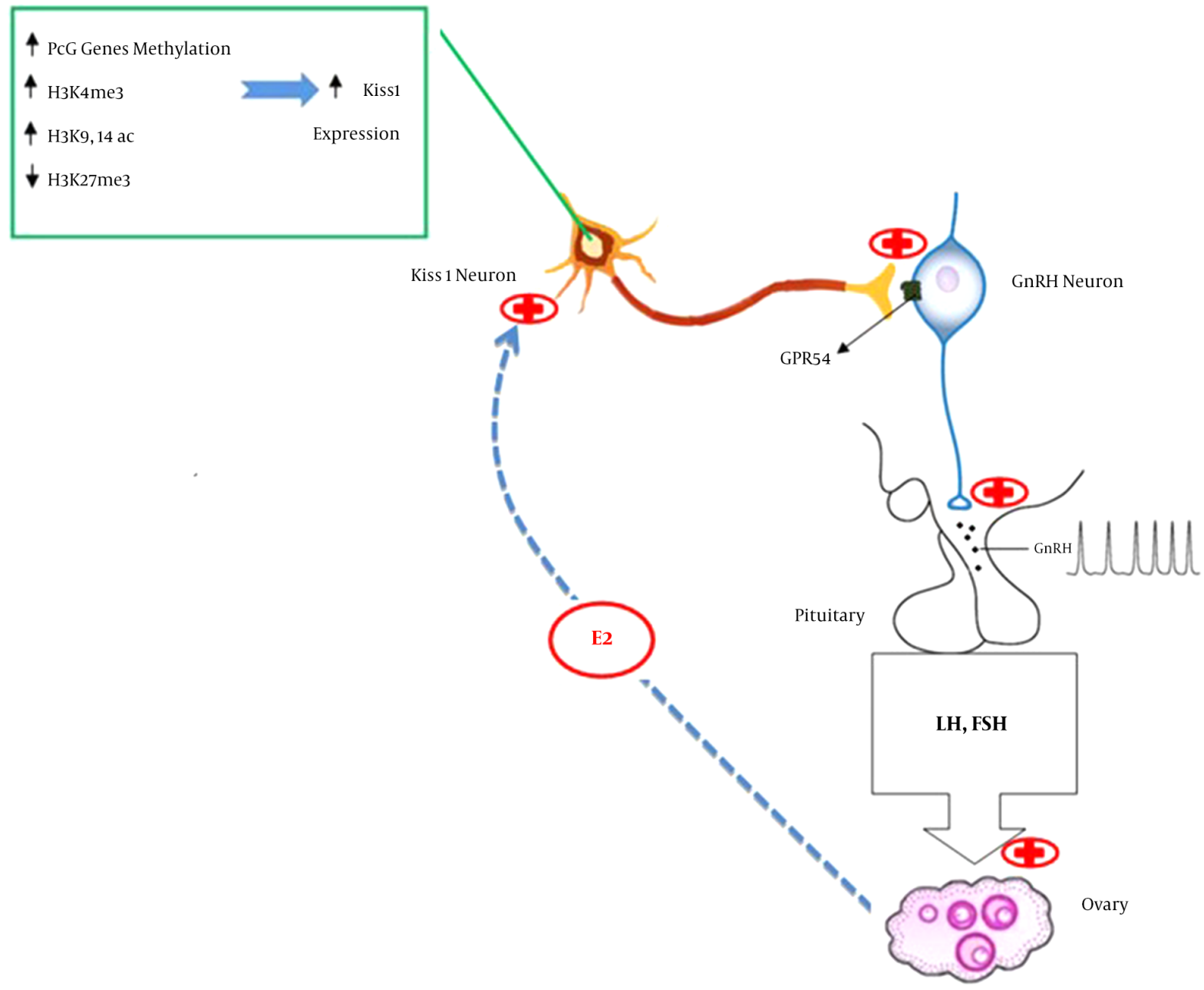

At around the time of pubertal onset, decreased expression of PcG proteins by DNA methylation along with histone 3 modifications increase Kiss1 mRNA expression resulting in elevated kisspeptin levels; this rise is accompanied by increased sensitivity to it and number of KISS1 neurons as well as enhancement of GPR54 signaling efficiency and expressio Abbreviations: PcG;Polycomb group, H3K9/14ac; Histon H3 acetylated at lysines 9/14, H3K4me3; Histon H3 trimethylated at lysine 4, H3K27me3; Histon H3 tri-methylated at lysine 27, E2; Estradiol.

tochemical analysis showed that Kiss1 mRNA is localized in syncytiotrophoblast; both these data together suggest the possible role of Kisspeptin in the regulation of trophoblast invasion. The highest expression levels of Kiss1 and Kiss1R mRNAs in trophoblast cells correspond with the maximum trophoblast invasion, when the aggressive process should be effectively regulated. Furthermore, in rodents the highest expression of both KISS1 and KISS1R was seen in the placenta. Studies have shown that Kisspeptin appears to control trophoblast migration via down-regulating the activity of some MMPs (12).

Kiss1 and Kiss1R mRNAs have also been detected in the vascular system, including human aorta, coronary artery and umbilical vein, as well as in the placenta, pituitary, peripheral blood leukocytes, kidney, and pancreas $(33,48)$.

\subsection{Kisspeptin and Lactation}

There is a temporal increase in plasma oxytocin levels following IV administration of Kisspeptin 10 in female rats; nevertheless intra-cerebroventricular (icv) injection of Kisspeptin 10 did not effect circulating oxytocin levels. On the other hand, the disintegration of vagal afferent input blunted the release of oxytocin; all this evidence together was the basis of the hypothesis that Kisspeptin 
Figure 2. Kisspeptin (KP) Expression in the Ovary Mainly Occurs in the Granulosa Cells (GC) in Response to Preovulatory LH Surge

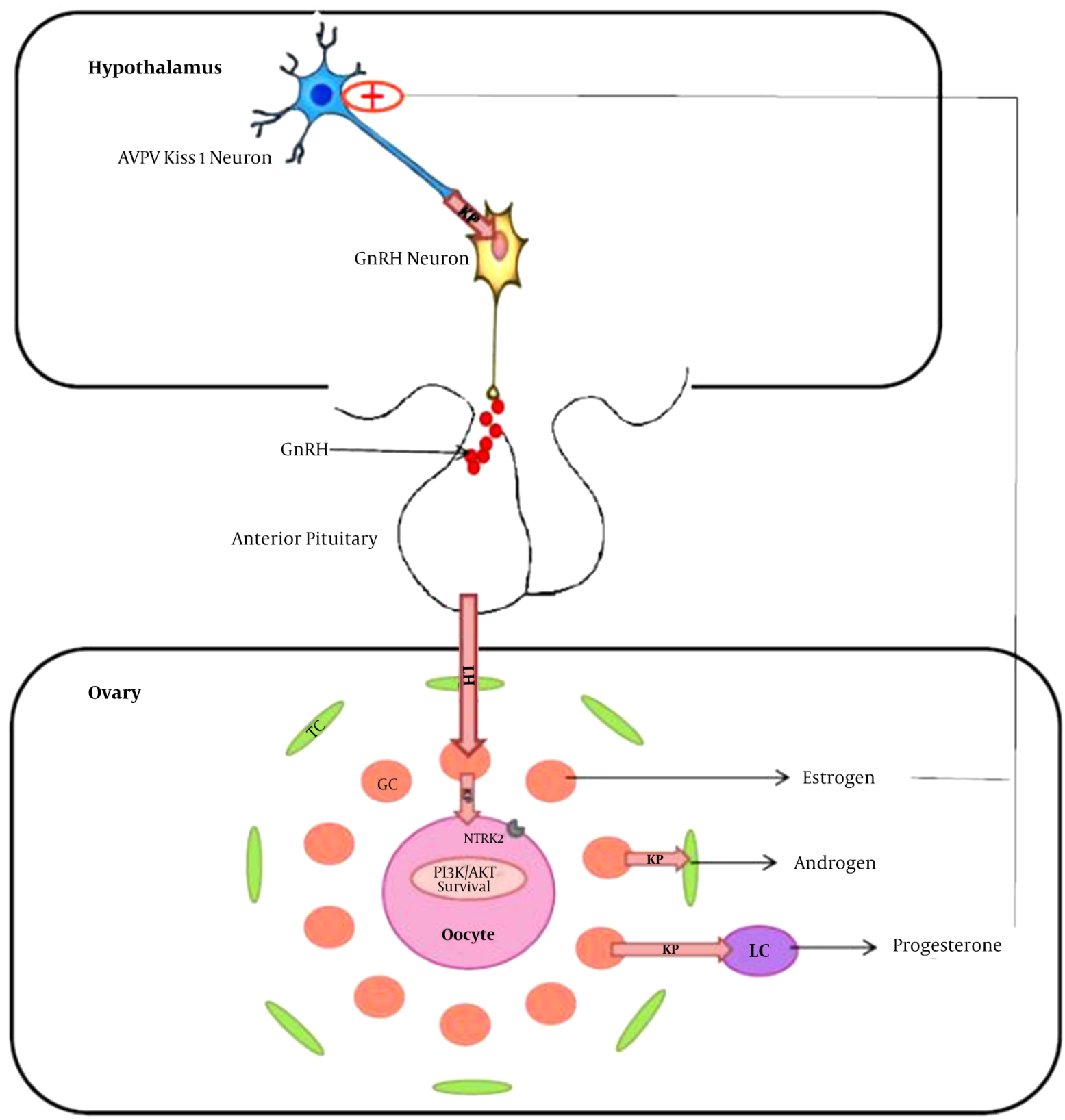

LH surge also induces the expression of the full length NTRK2 receptor, which with kisspeptin signaling drives oocyte survival through the PI3K/AKT pathway. In addition, kisspeptin stimulates steroid secretion by theca (TC) and luteal cells (LC).

10 acts as a hormone (rather than a neuropeptide) on peripheral targets and indirectly activates oxytocin neurons. Recently, it has been shown that central Kisspeptin 10 administration excited oxytocin neurons at the end of pregnancy and during lactation, indicating the required
Kisspeptin-induced secretion of oxytocin for parturition and lactation. Increased plasma Kisspeptin during pregnancy might hence accelerate oxytocin release, yet oxytocin receptor expression and oxytocin sensitivity remain low prior to childbirth (49). 
However, data has shown that prolactin administration in mice drastically suppressed Kisspeptin expression in the hypothalamus, thereby decreasing $\mathrm{GnRH}$ release. Again, using bromocriptine, as prolactin suppressor, was associated with significant increased Kiss1 mRNA expression in the rostral periventricular area of the third ventricle (RP3V) of mice. In addition, rats showed reduced expression of Kiss1 mRNA in the hypothalamus and LH secretion during lactation, due to which the estrous cycle was shut down. Indeed, in almost all mammals, lactation causes a period of infertility providing successful growth and survival of the offspring, and appropriate suppression of Kisspeptin expression contributes to lactational anovulation $(50,51)$.

\subsection{Kisspeptin and Aging}

Age-related changes in Kisspeptin signaling differ between rats and primates. In middle-aged rats decrease in Kisspeptin signaling precedes ovarian failure and E2 levels remain the same until they increase in persistent estrous rats $(52,53)$. In humans and monkeys postmenopausal increase in hypothalamic Kisspeptin levels appears to occur after ovarian failure and loss of E2 feedback, which could be related to the final stage of reproductive senescence in rats (persistent anestrus or persistent diestrus) and low E2 levels (52-55).

Compared to young animals, in middle-aged female rats, Kiss1 expression is reduced at the time of LH surge while central Kisspeptin infusion recovers LH release amplitude. On the other hand, GnRH neurons in young and reproductively healthy female hamsters expressed more cFos gene, (as an indicator of GnRH neuronal activity) on the afternoon of proestrus compared to their middle-aged counterparts; there was however no difference in the total number of GnRH-immunoreactive neurons between the 2 groups (52). Furthermore, the Vasoactive Intestinal Polypeptide(VIP) mRNA, yet not (arginine vasopressin)AVP mRNA, is attenuated in the suprachiasmatic nucleus (SCN) of middle-aged female hamsters; suppression of VIP signaling by direct infusion of VIP antisense oligonucleotides or antiserum into the SCN in young cycling female hamsters speeds up the decline in neural circuits, underlying ovulatory functioning. These findings suggest that age-related decline in reproductive competence may result, in part, from alterations in circadian signaling to the Kisspeptin system (56).

\subsection{Epigenetic Regulation of Kisspeptin}

Although KISS1 gene is expressed in both central and peripheral tissues, the mechanisms that determine the temporal and local expression of KISS1 gene are not well understood. Alterations in the expression of KISS1 may contribute to sexual differentiation, puberty onset, and progression in females. The KISS1 in the AVPV is expressed to a greater degree in females than males, which is responsible for the female-specific GnRH/LH surge (57). As mentioned earlier, sexual dimorphism in AVPV KISS1 gene expression seems to be caused during the prenatal critical period by exposure to testosterone. Several mechanisms may be involved in sexual differences in KISS1 expression in the AVPV, including epigenetic mechanisms (36).

Postnatal inhibition of histone deacetylase increased the number of AVPV KISS1 neurons in both male and female mice, yet, did not alter the AVPV KISS1 gender difference. This finding may indicate histone deacetylation contribution in some aspects of KISS1 neuron development in the AVPV (57). In addition, significant gender difference was seen in the CPG methylation degree of the KISS1 gene, mainly in the promoter region, with higher methylation levels in females than males. On the other hand, several of this sexually dimorphic KISS1 CpGs were in or near binding sites for transcriptional repressors. Thus, higher DNA methylation in females may decrease transcriptional repressor binding, leading to higher KISS1 expression. However, more studies are needed to address the mechanisms involved in sexual differentiation of the AVPV KISS1 system (57).

The ARC KISS1 neurons are considered to be involved in pubertal elevated GnRH/gonadotropin release, although several other studies have failed to identify major pubertal Kisspeptin increases in this region. Studies in prepubertal female rats have shown that PcG proteins, Eed, and Cbx7, are associated with the KISS1 promoter in the ARC. At the late juvenile stage, increased methylation of Eed and Cbx7 promoters reduced their expression, thus PcG proteins are evicted from the KISS1 promoter. This loss is accompanied by activating chromatin modifications at the promoter (Histon $\mathrm{H} 3$ acetylated at lysines 9/14, H3K9/14ac, Histon $\mathrm{H} 3$ trimethylated at lysine $4 \mathrm{H} 3 \mathrm{~K} 4 \mathrm{me} 3$, and perhaps histone demethylation) and KISS1 expression increases. It has been reported that DNA methylation inhibition prevented Kiss1 increase in the ARC KISS1 neurons and delayed puberty (36).

Furthermore, analysis of the KISS1 promoter region in the AVPV of rodents showed an activating histone $\mathrm{H} 3 \mathrm{mod}$ ification and $\mathrm{H} 3 \mathrm{~K} 9 / 14$ acetylation, induced by $\mathrm{E} 2$ at the time of the preovulatory gonadotropin surge. Estradiol also increases ER $\alpha$ binding to the KISS1 promoter in the AVPV at this time. It is likely that the estrogen-ER $\alpha$ complex on the KISS1 promoter region induces formation of a chromatin loop between the promoter and $3^{\prime}$ downstream regions of the KISS1 gene, which has been shown to act as an enhancer. However, further studies are needed to explain the molecular mechanisms controlling E2-induced AVPV KISS1 gene 
expression (37).

In contrast, E2 decreases $\mathrm{H} 3 \mathrm{~K} 9 / 14$ acetylation at the KISS1 promoter in the ARC and does not increase ER $\alpha$ binding to this region at the preovulatory period. In addition, ovariectomy increased histone $\mathrm{H} 3 \mathrm{~K} 9 / 14$ acetylation in the KISS1 promoter region and gene expression in the ARC and E2 treatment abolished this effect. It is possible that in the absence of estrogen some chromatin loops form between the promoter region and the $5^{\prime}$ upstream enhancer (an ARC-specific enhancer) of the KISS1 gene. In contrast, KISS1 promoter DNA methylation did not change in the AVPV and ARC, indicating that DNA methylation may have no role in KISS1 promoter regulation $(37,57)$.

\subsection{Kisspeptin and Reproductive Disorders}

In the past few years, loss-of-function mutations of KISS1 and KISS1-R have been reported in patients with IHH $(13-15,27)$. IHH is associated with reduced GnRH signaling and low circulating gonadotropin levels, which leads to the impairment of pubertal maturation and reproductive function (27).

In addition, hypothalamic KISS1 expression is reduced (masculinization of the AVPV population) in animal models of PCOS, exposed to excess androgen during critical periods of early life $(30,58,59)$. In line with the current data, neonatal gonadectomy of male rats resulted in elevated Kiss1 mRNAs and hence, feminization in the AVPV population $(30,60,61)$ On the other hand, animal models of PCOS have increased levels of Kiss1 mRNA in peripheral tissues such as the ovaries and fat (62). Moreover, high plasma levels of Kisspeptin have been reported in PCOS patients, which may reflect its relationship to pathological conditions in ovaries $(63,64)$. However, GnRH neuron activity and LH secretion enhances in pre and/or post-natally androgenized animal models, regardless of reduced KISS1 expression (62).

Pathological conditions, such as PCOS, are associated with abnormal pulsatile GnRH secretion. In PCOS, the GnRH pacemaker becomes less responsive to ovarian steroid negative feedback (particularly progesterone) due to elevated androgen levels, leading to increased LH secretion and perturbed LH-FSH ratios $(62,65)$. Since hypothalamic KISS1 neurons relay gonadal steroid regulation on the HPG axis, hypothalamic Kiss1 mRNA levels are abnormal in PCOS subjects. Again, ovarian Kisspeptin alterations may contribute to the ovarian phenotype of $\operatorname{PCOS}(6,62)$.

On the other hand, recent studies have suggested that peripheral infusion of Kisspeptin stimulates gonadotropin release in healthy subjects, and in individuals with $\mathrm{IHH}$, hypothalamic amenorrhea (HA), and anovulation (66). Therefore, the Kisspeptin and its agonists/antagonists may provide a potential treatment for disorders of reproduction, characterized by both low and high GnRH pulsatility $(67,68)$.

\section{Conclusions}

In summary, recent studies has clearly demonstrated involvement of the KISS1/GPR54 system in the physiology and pathophysiology of the HPG axis. Kisspeptin is a very potent stimulator of GnRH secretion and mediates negative and positive feedback effects of sex steroids on the brain (68). Two major populations of KISS1-expressing neurons located at the POA and ARC have been detected in the mammalian hypothalamus (30). Kisspeptin has been implicated in the regulation of puberty onset, ovarian function, trophoblast invasion, fertility regulation, parturition, and lactation. Thus, it may offer a potential treatment for reproductive disorders, characterized by low or high gonadotropins, such as IHH, HA, and PCOS. Current medications for female infertility disorders often include hormone replacement (estrogen, progestin, FSH, and LH) to help menstrual regulation and ovulation and/or in vitro fertilization (most commonly using hCG). However, more research is needed to further explore if Kisspeptin could replace or be used in conjunction with current gold-standard therapies, in the treatment of reproductive disorders.

\section{Acknowledgments}

The authors wish to acknowledge Ms. Niloofar Shiva for critical editing of English grammar and syntax of the manuscript.

\section{Footnotes}

Declaration of Interests: Neither authors had any conflict of interest to declare in relation to this manuscript.

Funding/Support: The study was funded by the Research Institute for Endocrine Sciences, Shahid Beheshti University of Medical Sciences.

\section{References}

1. Thompson IR, Kaiser UB. GnRH pulse frequency-dependent differential regulation of $\mathrm{LH}$ and FSH gene expression. Mol Cell Endocrinol. 2014;385(1-2):28-35. doi: 10.1016/j.mce.2013.09.012. [PubMed: 24056171].

2. Molter-Gerard C, Fontaine J, Guerin S, Taragnat C. Differential regulation of the gonadotropin storage pattern by gonadotropin-releasing hormone pulse frequency in the ewe. Biol Reprod. 1999;60(5):1224-30. [PubMed: 10208988].

3. Gore AC, Oung T, Woller MJ. Age-related changes in hypothalamic gonadotropin-releasing hormone and N-methyl-D-aspartate receptor gene expression, and their regulation by oestrogen, in the female rat. J Neuroendocrinol. 2002;14(4):300-9. [PubMed:11963827]. 
4. d'Anglemont de Tassigny X, Colledge WH. The role of kisspeptin signaling in reproduction. Physiology (Bethesda). 2010;25(4):207-17. doi: 10.1152/physiol.00009.2010. [PubMed: 20699467].

5. Lents CA, Heidorn NL, Barb CR, Ford JJ. Central and peripheral administration of kisspeptin activates gonadotropin but not somatotropin secretion in prepubertal gilts. Reproduction. 2008;135(6):879-87. doi: 10.1530/REP-07-0502. [PubMed: 18339687].

6. Witchel SF, Tena-Sempere M. The Kiss1 system and polycystic ovary syndrome: lessons from physiology and putative pathophysiologic implications. Fertil Steril. 2013;100(1):12-22. doi: 10.1016/j.fertnstert.2013.05.024. [PubMed: 23809625].

7. Kotani M, Detheux M, Vandenbogaerde A, Communi D, Vanderwinden JM, Le Poul E, et al. The metastasis suppressor gene KiSS-1 encodes kisspeptins, the natural ligands of the orphan $G$ proteincoupled receptor GPR54. J Biol Chem. 2001;276(37):34631-6. doi: 10.1074/jbc.M104847200. [PubMed: 11457843].

8. Tena-Sempere $M$. The roles of kisspeptins and $G$ proteincoupled receptor-54 in pubertal development. Curr Opin Pediatr. 2006;18(4):442-7. doi: 10.1097/01.mop.0000236396.79580.cc. [PubMed: 16915001].

9. Tanco VM, Whitlock BK, Jones MA, Wilborn RR, Brandebourg TD, Foradori CD. Distribution and regulation of gonadotropin-releasing hormone, kisspeptin, RF-amide related peptide-3, and dynorphin in the bovine hypothalamus. PeerJ. 2016;4:ee1833. doi: 10.7717/peerj.1833. [PubMed: 27014517]

10. Lee DK, Nguyen T, O'Neill GP, Cheng R, Liu Y, Howard AD, et al. Discovery of a receptor related to the galanin receptors. FEBS Lett. 1999;446(1):103-7. [PubMed: 10100623].

11. Muir AI, Chamberlain L, Elshourbagy NA, Michalovich D, Moore DJ, Calamari A, et al. AXOR12, a novel human G protein-coupled receptor, activated by the peptide KiSS-1.J Biol Chem. 2001;276(31):28969-75. doi: 10.1074/jbc.M102743200. [PubMed: 11387329].

12. Reynolds RM, Logie JJ, Roseweir AK, McKnight AJ, Millar RP. A role for kisspeptins in pregnancy: facts and speculations. Reproduction. 2009;138(1):1-7. doi: 10.1530/REP-09-0026. [PubMed: 19336473].

13. Funes S, Hedrick JA, Vassileva G, Markowitz L, Abbondanzo S, Golovko A, et al. The KiSS-1 receptor GPR54 is essential for the development of the murine reproductive system. Biochem Biophys Res Commun. 2003;312(4):1357-63. [PubMed: 14652023].

14. de Roux N, Genin E, Carel JC, Matsuda F, Chaussain JL, Milgrom E. Hypogonadotropic hypogonadism due to loss of function of the KiSS1-derived peptide receptor GPR54. Proc Natl Acad Sci U S A. 2003;100(19):10972-6. doi: 10.1073/pnas.1834399100. [PubMed: 12944565]

15. Seminara SB, Messager S, Chatzidaki EE, Thresher RR, Acierno JJ, Shagoury JK, et al. The GPR54 gene as a regulator of puberty. $N$ Engl J Med. 2003;349(17):1614-27. doi: 10.1056/NEJMoa035322. [PubMed: 14573733].

16. Castellano JM, Gaytan M, Roa J, Vigo E, Navarro VM, Bellido C, et al. Expression of KiSS-1 in rat ovary: putative local regulator of ovulation? Endocrinology. 2006;147(10):4852-62. doi: 10.1210/en.2006-0117. [PubMed: 16825322].

17. Kauffman AS, Clifton DK, Steiner RA. Emerging ideas about kisspeptinGPR54 signaling in the neuroendocrine regulation of reproduction. Trends Neurosci. 2007;30(10):504-11. doi: 10.1016/j.tins.2007.08.001. [PubMed: 17904653].

18. Votsi E, Roussos D, Katsikis I, Karkanaki A, Kita M, Panidis D. Kisspeptins: a multifunctional peptide system with a role in reproduction, cancer and the cardiovascular system. Hippokratia. 2008;12(4):205-10. [PubMed: 19554077].

19. West A, Vojta PJ, Welch DR, Weissman BE. Chromosome localization and genomic structure of the KiSS-1 metastasis suppressor gene (KISS1). Genomics. 1998;54(1):145-8. doi: 10.1006/geno.1998.5566. [PubMed: 9806840].

20. Li D, Yu W, Liu M. Regulation of KiSS1 gene expression. Peptides. 2009;30(1):130-8. doi:10.1016/j.peptides.2008.09.025. [PubMed:
18996159].

21. Mueller JK, Dietzel A, Lomniczi A, Loche A, Tefs K, Kiess W, et al. Transcriptional regulation of the human KiSS1 gene. Mol Cell Endocrinol. 2011;342(1-2):8-19. doi: 10.1016/j.mce.2011.04.025. [PubMed: 21672609].

22. Castellano JM, Wright H, Ojeda SR, Lomniczi A. An alternative transcription start site yields estrogen-unresponsive Kiss1 mRNA transcripts in the hypothalamus of prepubertal female rats. Neuroendocrinology. 2014;99(2):94-107. doi: 10.1159/000362280. [PubMed: 24686008].

23. Silveira LG, Noel SD, Silveira-Neto AP, Abreu AP, Brito VN, Santos MG, et al. Mutations of the KISS1 gene in disorders of puberty. J Clin Endocrinol Metab. 2010;95(5):2276-80. doi: 10.1210/jc.2009-2421. [PubMed: 20237166].

24. Rhie YJ, Lee KH, Ko JM, Lee WJ, Kim JH, Kim HS. KISS1 gene polymorphisms in Korean girls with central precocious puberty. J Korean Med Sci. 2014;29(8):1120-5. doi: 10.3346/jkms.2014.29.8.1120. [PubMed: 25120323].

25. Mazaheri A, Hashemipour M, Salehi M, Behnam M, Hovsepian S, Hassanzadeh A. Mutation of kisspeptin 1 gene in children with precocious puberty in isfahan city. Int J Prev Med. 2015;6:41. doi: 10.4103/2008-7802.156839. [PubMed: 26015864].

26. Huijbregts L, Roze C, Bonafe G, Houang M, Le Bouc Y, Carel JC, et al. DNA polymorphisms of the KiSS1 3' untranslated region interfere with the folding of a G-rich sequence into G-quadruplex. Mol Cell Endocrinol. 2012;351(2):239-48. doi: 10.1016/j.mce.2011.12.014. [PubMed: 22230814].

27. Topaloglu AK, Tello JA, Kotan LD, Ozbek MN, Yilmaz MB, Erdogan S, et al. Inactivating KISS1 mutation and hypogonadotropic hypogonadism. N Engl J Med. 2012;366(7):629-35. doi: 10.1056/NEJMoa1111184. [PubMed: 22335740].

28. An X, Ma T, Hou J, Fang F, Han P, Yan Y, et al. Association analysis between variants in KISS1 gene and litter size in goats. BMC Genet. 2013;14:63. doi: 10.1186/1471-2156-14-63. [PubMed: 23915023].

29. Kauffman AS. Coming of age in the kisspeptin era: sex differences, development, and puberty. Mol Cell Endocrinol. 2010;324(1-2):51-63. doi: 10.1016/j.mce.2010.01.017. [PubMed: 20083160].

30. Kauffman AS, Gottsch ML, Roa J, Byquist AC, Crown A, Clifton DK, et al. Sexual differentiation of Kiss1 gene expression in the brain of the rat. Endocrinology. 2007;148(4):1774-83. doi: 10.1210/en.2006-1540. [PubMed: 17204549].

31. Tena-Sempere M. Kisspeptin/GPR54 system as potential target for endocrine disruption of reproductive development and function. Int J Androl. 2010;33(2):360-8. doi: 10.1111/j.1365-2605.2009.01012.x. [PubMed: 19906185].

32. Adachi S, Yamada S, Takatsu Y, Matsui H, Kinoshita M, Takase K, et al. Involvement of anteroventral periventricular metastin/kisspeptin neurons in estrogen positive feedback action on luteinizing hormone release in female rats.J Reprod Dev. 2007;53(2):367-78. [PubMed: 17213691].

33. Pinilla L, Aguilar E, Dieguez C, Millar RP, Tena-Sempere M. Kisspeptins and reproduction: physiological roles and regulatory mechanisms. Physiol Rev. 2012;92(3):1235-316. doi: 10.1152/physrev.00037.2010. [PubMed: 22811428].

34. Mayer C, Acosta-Martinez M, Dubois SL, Wolfe A, Radovick S, Boehm $\mathrm{U}$, et al. Timing and completion of puberty in female mice depend on estrogen receptor alpha-signaling in kisspeptin neurons. Proc Natl Acad Sci U S A. 2010;107(52):22693-8. doi: 10.1073/pnas.1012406108. [PubMed: 21149719].

35. Shahab M, Mastronardi C, Seminara SB, Crowley WF, Ojeda SR, Plant TM. Increased hypothalamic GPR54 signaling: a potential mechanism for initiation of puberty in primates. Proc Natl Acad Sci $U$ S A. 2005;102(6):2129-34. doi: 10.1073/pnas.0409822102. [PubMed: 15684075].

36. Lomniczi A, Loche A, Castellano JM, Ronnekleiv OK, Bosch $\mathrm{M}$, Kaidar G, et al. Epigenetic control of female puberty. Nat Neurosci. 
2013;16(3):281-9. doi: 10.1038/nn.3319. [PubMed: 23354331].

37. Tomikawa J, Uenoyama Y, Ozawa M, Fukanuma T, Takase K, Goto $\mathrm{T}$, et al. Epigenetic regulation of Kiss1 gene expression mediating estrogen-positive feedback action in the mouse brain. Proc Natl Acad Sci U S A. 2012;109(20):E1294-301. doi: 10.1073/pnas.1114245109. [PubMed: 22505735].

38. Gutierrez-Pascual E, Martinez-Fuentes AJ, Pinilla L, Tena-Sempere M, Malagon MM, Castano JP. Direct pituitary effects of kisspeptin: activation of gonadotrophs and somatotrophs and stimulation of luteinising hormone and growth hormone secretion. $J$ Neuroendocrinol. 2007;19(7):521-30. doi: 10.1111/j.1365-2826.2007.01558.x. [PubMed: 17532794].

39. Witham EA, Meadows JD, Hoffmann HM, Shojaei S, Coss D, Kauffman AS, et al. Kisspeptin regulates gonadotropin genes via immediate early gene induction in pituitary gonadotropes. Mol Endocrinol. 2013;27(8):1283-94. doi: 10.1210/me.2012-1405. [PubMed: 23770611].

40. Gottsch ML, Cunningham MJ, Smith JT, Popa SM, Acohido BV, Crowley $\mathrm{WF}$, et al. A role for kisspeptins in the regulation of gonadotropin secretion in the mouse. Endocrinology. 2004;145(9):4073-7. doi: 10.1210/en.2004-0431. [PubMed: 15217982].

41. Richard N, Galmiche G, Corvaisier S, Caraty A, Kottler ML. KiSS-1 and GPR54 genes are co-expressed in rat gonadotrophs and differentially regulated in vivo by oestradiol and gonadotrophin-releasing hormone. I Neuroendocrinol. 2008;20(3):381-93. doi: 10.1111/j.13652826.2008.01653.x. [PubMed: 18208554].

42. Smith JT, Rao A, Pereira A, Caraty A, Millar RP, Clarke IJ. Kisspeptin is present in ovine hypophysial portal blood but does not increase during the preovulatory luteinizing hormone surge: evidence that gonadotropes are not direct targets of kisspeptin in vivo. Endocrinology. 2008;149(4):1951-9. doi:10.1210/en.2007-1425. [PubMed: 18162520].

43. Luque RM, Cordoba-Chacon J, Gahete MD, Navarro VM, Tena-Sempere M, Kineman RD, et al. Kisspeptin regulates gonadotroph and somatotroph function in nonhuman primate pituitary via common and distinct signaling mechanisms. Endocrinology. 2011;152(3):957-66. doi: 10.1210/en.2010-1142. [PubMed: 21209013].

44. Shahed A, Young KA. Differential ovarian expression of KiSS-1 and GPR-54 during the estrous cycle and photoperiod induced recrudescence in Siberian hamsters (Phodopus sungorus). Mol Reprod Dev. 2009;76(5):444-52. doi: 10.1002/mrd.20972. [PubMed:18937338].

45. Revel FG, Saboureau M, Masson-Pevet M, Pevet P, Mikkelsen JD, Simonneaux V. Kisspeptin mediates the photoperiodic control of reproduction in hamsters. Curr Biol. 2006;16(17):1730-5. doi: 10.1016/j.cub.2006.07.025. [PubMed: 16950111].

46. Anderson RA. Brainwork in the ovary: kisspeptin and BDNF signaling converge to ensure oocyte survival. Endocrinology. 2014;155(8):2751-3. doi: 10.1210/en.2014-1447. [PubMed: 25036649].

47. Peng J, Tang M, Zhang BP, Zhang P, Zhong T, Zong T, et al. Kisspeptin stimulates progesterone secretion via the Erk1/2 mitogen-activated protein kinase signaling pathway in rat luteal cells. Fertil Steril. 2013;99(5):1436-1443 e1. doi: 10.1016/j.fertnstert.2012.12.008. [PubMed: 23312234].

48. Park DW, Lee SK, Hong SR, Han AR, Kwak-Kim J, Yang KM. Expression of Kisspeptin and its receptor GPR54 in the first trimester trophoblast of women with recurrent pregnancy loss. Am J Reprod Immunol. 2012;67(2):132-9. doi:10.1111/j.1600-0897.2011.01073.x. [PubMed: 21996032].

49. Scott V, Brown $\mathrm{CH}$. Beyond the $\mathrm{GnRH}$ axis: kisspeptin regulation of the oxytocin system in pregnancy and lactation. Adv Exp Med Biol. 2013;784:201-18. doi: 10.1007/978-1-4614-6199-9_10. [PubMed: 23550008].

50. Brown RS, Herbison AE, Grattan DR. Prolactin regulation of kisspeptin neurones in the mouse brain and its role in the lactationinduced suppression of kisspeptin expression. J Neuroendocrinol. 2014;26(12):898-908. doi: 10.1111/jne.12223. [PubMed: 25207795].

51. Grattan DR. 60 YEARS OF NEUROENDOCRINOLOGY:The hypothalamoprolactin axis. J Endocrinol. 2015;226(2):T101-22. doi: 10.1530/JOE-15-
0213. [PubMed: 26101377]

52. Lederman MA, Lebesgue D, Gonzalez VV, Shu J, Merhi ZO, Etgen AM, et al. Age-related LH surge dysfunction correlates with reduced responsiveness of hypothalamic anteroventral periventricular nucleus kisspeptin neurons to estradiol positive feedback in middle-aged rats. Neuropharmacology. 2010;58(1):314-20. doi: 10.1016/j.neuropharm.2009.06.015. [PubMed:19559035].

53. Neal-Perry G, Lebesgue D, Lederman M, Shu J, Zeevalk GD, Etgen AM The excitatory peptide kisspeptin restores the luteinizing hormone surge and modulates amino acid neurotransmission in the medial preoptic area of middle-aged rats. Endocrinology. 2009;150(8):3699708. doi: 10.1210/en.2008-1667. [PubMed: 19423763].

54. Eghlidi DH, Haley GE, Noriega NC, Kohama SG, Urbanski HF. Influence of age and 17beta-estradiol on kisspeptin, neurokinin $\mathrm{B}$, and prodynorphin gene expression in the arcuate-median eminence of female rhesus macaques. Endocrinology. 2010;151(8):3783-94. doi: 10.1210/en.2010-0198. [PubMed: 20519367].

55. Rance NE. Menopause and the human hypothalamus: evidence for the role of kisspeptin/neurokinin B neurons in the regulation of estrogen negative feedback. Peptides. 2009;30(1):111-22. doi 10.1016/j.peptides.2008.05.016. [PubMed:18614256].

56. Kriegsfeld LJ. Circadian regulation of kisspeptin in female reproductive functioning. Adv Exp Med Biol. 2013;784:385-410. doi:10.1007/9781-4614-6199-9_18. [PubMed: 23550016].

57. Uenoyama Y, Tomikawa J, Inoue N, Goto T, Minabe S, Ieda N, et al Molecular and Epigenetic Mechanism Regulating Hypothalamic Kiss1 Gene Expression in Mammals. Neuroendocrinology. 2016;103(6):6409. doi: 10.1159/000445207. [PubMed: 26964105].

58. Cernea M, Padmanabhan V, Goodman RL, Coolen LM, Lehman MN Prenatal Testosterone Treatment Leads to Changes in the Morphology of KNDy Neurons, Their Inputs, and Projections to GnRH Cells in Female Sheep. Endocrinology. 2015;156(9):3277-91. doi:10.1210/en.20141609. [PubMed: 26061725].

59. Takumi K, Iijima N, Iwata K, Higo S, Ozawa $\mathrm{H}$. The effects of gonadal steroid manipulation on the expression of Kiss1 mRNA in rat arcuate nucleus during postnatal development. J Physiol Sci. 2012;62(6):45360. doi: 10.1007/s12576-012-0222-y. [PubMed: 22851291].

60. Nakamura S, Uenoyama Y, Ikegami K, Dai M, Watanabe Y, Takahashi C, et al. Neonatal Kisspeptin is Steroid-Independently Required for Defeminisation and Peripubertal Kisspeptin-Induced Testosterone is Required for Masculinisation of the Brain: A Behavioural Study Using Kiss1 Knockout Rats. J Neuroendocrinol. 2016;28(10) doi: 10.1111/jne.12409. [PubMed: 27344056].

61. Kauffman AS. Sexual differentiation and the Kiss1 system: hormonal and developmental considerations. Peptides. 2009;30(1):83-93. doi: 10.1016/j.peptides.2008.06.014. [PubMed: 18644414].

62. Brown RE, Wilkinson DA, Imran SA, Caraty A, Wilkinson M. Hypothalamic kiss1 mRNA and kisspeptin immunoreactivity are reduced in a rat model of polycystic ovary syndrome (PCOS). Brain Res. 2012;1467:1-9. doi: 10.1016/j.brainres.2012.05.049. [PubMed: 22668987].

63. Jeon YE, Lee KE, Jung JA, Yim SY, Kim H, Seo SK, et al. Kisspeptin, leptin, and retinol-binding protein 4 in women with polycystic ovary syndrome. Gynecol Obstet Invest. 2013;75(4):268-74. doi: 10.1159/000350217. [PubMed: 23571154].

64. Chen XL, Mo YQ, Li L, Chen YX, Li Y, Zhang QX, et al. Plasma metastin in adolescent polycystic ovary syndrome [in Chinese]. Zhonghua Fu Chan Ke Za Zhi. 2009;44(10):745-9. [PubMed: 20078960].

65. Skorupskaite K, George JT, Anderson RA. The kisspeptin-GnRH pathway in human reproductive health and disease. Hum Reprod Up date. 2014;20(4):485-500. doi: 10.1093/humupd/dmu009. [PubMed: 24615662].

66. Chan YM. Effects of kisspeptin on hormone secretion in humans. Adv Exp Med Biol. 2013;784:89-112. doi: 10.1007/978-1-4614-6199-9_5. [PubMed: 23550003].

67. Matsui H, Asami T. Effects and therapeutic potentials of kisspeptin 
analogs: regulation of the hypothalamic-pituitary-gonadal axis. Neuroendocrinology. 2014;99(1):49-60. doi: 10.1159/000357809. [PubMed: 24356680].

68. Clarke H, Dhillo WS, Jayasena CN. Comprehensive Review on
Kisspeptin and Its Role in Reproductive Disorders. Endocrinol Metab (Seoul). 2015;30(2):124-41. doi: 10.3803/EnM.2015.30.2.124. [PubMed: 26194072]. 